\title{
Anti-adipogenic effect of a turmeric extract-loaded nanoemulsion in 3T3-L1 preadipocytes and high fat diet-fed mice
}

\author{
Jung Seok HWANG ${ }^{1}$, Su Bi LEE ${ }^{2}$, Mi-Jung CHOI ${ }^{1}$, Jun Tae $\mathrm{KIM}^{2}$, Han Geuk SEO ${ }^{1 \star}$ (D)
}

\begin{abstract}
We investigated the effects of a turmeric extract-loaded nanoemulsion (TENE) on lipid accumulation in 3T3-L1 adipocytes and in mice fed a high fat diet (HFD). The accumulation of intracellular lipid in 3T3-L1 adipocytes was significantly inhibited by TENE, according to Oil red $\mathrm{O}$ and Nile Red staining. This inhibitory effect of TENE on adipocyte differentiation was associated with lower expression levels of the adipocyte-specific genes, PPAR $\gamma$, aP2, and C/EBP $\alpha$. In HepG2 hepatocytes, TENE attenuated palmitate-induced intracellular accumulation of lipid and ROS. In mice fed a HFD, TENE significantly reduced the serum levels of total cholesterol, triglycerides, and LDL and increased HDL levels. These effects of TENE were accompanied by reductions in the expression of PPAR $\gamma, \mathrm{aP} 2$, and $\mathrm{C} / \mathrm{EBP} \alpha$ in adipose tissue and smaller epididymal adipocytes. These results suggest that TENE inhibits adipogenesis by reducing expression of adipogenic transcription factors, thereby substantiating the potential to ameliorate metabolic disorders related to obesity.
\end{abstract}

Keywords: adipogenic differentiation; high fat diet; nanoemulsion; turmeric; 3T3-L1 preadipocytes.

Practical Application: Anti-adipogenic effect of turmeric nanoemulsion.

\section{Introduction}

An increase in the number of adipocytes (hyperplasia) due to adipocyte differentiation and an increase in the size of adipocytes (hypertrophy) are both contributors to the development of obesity (Guo et al., 2015; Shepherd et al., 1993; Spalding et al., 2008). An increase in adipose tissue mass is paralleled by higher prevalence of obesity-related complications, such as hyperlipidemia, hypertension, type 2 diabetes, and nonalcoholic fatty liver disease (Kopelman, 2000; Spalding et al., 2008). An improved understanding of adipocyte differentiation and function is critical to accelerate the development of drugs for the treatment of obesity and its complications.

The cellular and molecular mechanisms underlying adipocyte differentiation have mainly been established by studying in vitro models of preadipocytes derived from the mouse, such as the 3T3-L1 and 3T3-F442A cell lines (Gregoire et al., 1998; Rosen \& MacDougald, 2006). Upon treatment with inducers of adipogenesis, including glucocorticoid, insulin, and inhibitors of cyclic AMP phosphodiesterase, a process known as mitotic clonal expansion is initiated, causing growth-arrested confluent preadipocytes to re-enter the cell cycle, thereby contributing to adipocyte hyperplasia (Haslam \& James, 2005; Rosen \& MacDougald, 2006). Adipogenesis is mediated by the activation of a programmed series of gene transcription events, which involves the upregulation of adipogenic transcription factors, such as CCAAT/enhancer-binding protein (C/EBP) $\alpha / \beta$ and peroxisome proliferator-activated receptor (PPAR) $\gamma$. This leads to higher expression of adipocyte protein 2 (aP2), a marker of terminal adipocyte differentiation (Coe et al., 1999; Farmer, 2006; Guo et al., 2012; Rosen \& MacDougald, 2006; Wakabayashi et al., 2009).

Turmeric, Curcuma longa L., a perennial herb of the Zingiberaceae family, has been widely used for centuries as a spice, food preservative, coloring material, and traditional medicine in South Asia, Africa, and Latin America, including in India and China (Araújo \& Leon, 2001; Gupta et al., 2013). Although the major compound responsible for the biological activities of turmeric is curcumin, which constitutes $2-5 \%$ of the raw plant material, numerous other chemical entities, including alkaloids, sterols, polyphenols, and terpenoids, have been identified in turmeric and these also exhibit diverse pharmacological effects (Aggarwal et al., 2013; Gupta et al., 2013). These effects include amelioration of carrageenan-induced inflammation (Mukhopadhyay et al., 1982) and lipid peroxidation (Reddy \& Lokesh, 1992; Reddy \& Lokesh, 1994), anti-tumor effects (Huang et al., 1988; Huang et al., 1991), and anti-bacterial (Sathishkumar et al., 2010; Yano et al., 2006) and anti-protozoal activities (Rasmussen et al., 2000). In addition, the ethyl acetate fraction of turmeric partially inhibits lipogenesis by regulating expression of genes involved in glucose uptake and lipolysis (Lee et al., 2010). Furthermore, turmeric polyphenols protected adipocytes against oxidative stress by inhibiting the hydrogen peroxide-induced production of proinflammatory cytokines and reactive oxygen species via

Received 19 Jun., 2018

Accepted: 15 Dec., 2018

${ }^{1}$ Department of Food Science and Biotechnology of Animal Resources, College of Sang-Huh Life Science, Konkuk University, 120 Neungdong-ro, Gwangjin-Gu, Seoul 05029,

Korea

${ }^{2}$ Department of Food Science and Technology, Keimyung University, 1095 Dalgubeol-daero, Dalseo-Gu, Daegu 42601, Korea

*Correspondence to: hgseo@konkuk.ac.kr 
upregulation of antioxidant enzymes, such as superoxide dismutase and catalase (Septembre-Malaterre et al., 2016). However, the cellular and molecular mechanisms underlying the biological effects of turmeric extracts on adipocyte differentiation have not been fully elucidated.

In this study, we have investigated the effects of a turmeric extract-loaded nanoemulsion (TENE) on adipogenesis in 3T3-L1 adipocytes and in mice fed a high fat diet (HFD), paying particular attention to the expression of the genes implicated in adipocyte differentiation (PPAR $\gamma, \mathrm{C} / \mathrm{EBP} \alpha$, and $\mathrm{aP} 2)$. Our results indicate that TENE inhibits adipogenesis by reducing expression of adipogenic transcription factors, and therefore has the potential to ameliorate metabolic disorders related to obesity.

\section{Materials and methods}

\subsection{Materials}

Dimethyl sulfoxide (DMSO), dexamethasone, isobutyl-1-methylxanthine (IBMX), insulin, trypan blue, Oil red $\mathrm{O}$, Nile Red, palmitate, chloromethyl-2',7'-dichlorofluorescein diacetate (CM- $\left.\mathrm{H}_{2} \mathrm{DCF}-\mathrm{DA}\right)$, and polyclonal rabbit anti- $\beta$-antibody were purchased from Sigma-Aldrich (St. Louis, MO, USA). Turmeric powder was provided by the Ottogi Co., Ltd. (Anyang, Gyeonggi-do, Korea). Medium chain triglyceride (MCT) oil was purchased from NOW Foods (Elmhurst, IL, USA). Tween-80 and soy lecithin were purchased from Daejung Chemical (Seoul, Korea) and ESFOOD (Gunpo, Gyeonggi-do, Korea), respectively. Polyclonal antibodies specific for $\mathrm{C} / \mathrm{EBP} \alpha$ and $\mathrm{aP} 2$, and a monoclonal antibody specific for PPAR $\gamma$, were obtained from Santa Cruz Biotechnology (Santa Cruz, CA, USA).

\subsection{Preparation and characterization of Turmeric Extract-Loaded Nanoemulsion (TENE)}

Turmeric powder was extracted using 50\% ethanol and shaking for $24 \mathrm{~h}$, and the solvent was evaporated under vacuum to concentrate the extract. TENE was prepared by ultrasonication as follows. The oil phase was prepared by dissolving $173.92 \mathrm{~g}$ turmeric extract and $86.96 \mathrm{~g}$ MCT oil containing $26.09 \mathrm{~g}$ soy lecithin, while the aqueous phase was prepared by mixing $17.39 \mathrm{~g}$ tween-80, $173.9 \mathrm{~mL}$ turmeric extract, and $869.57 \mathrm{~mL}$ distilled water. A coarse emulsion was prepared by stirring at room temperature for $2 \mathrm{~h}$. Then, a nanoemulsion was prepared by high speed homogenization (HG-15D, Daihan Scientific Co., Ltd., Wonju, Korea) of the coarse emulsion at 5,000 rpm for $10 \mathrm{~min}$, with ultrasonication using a Vibra Cell (VCX-750, Sonics \& Materials, Inc., Sandy Hook, USA) for $15 \mathrm{~min}$, and a high pressure homogenization under 10,000 psi for three cycles. TENE powder was prepared by spray drying (KL-8, Seo Gang Engineering Co., Ltd., Cheonan, Korea) of 1,000 mL TENE with $113.06 \mathrm{~g}$ dextrin. The curcumin content of the TENE was determined by spectrophotometric methods. To determine the physicochemical properties of the TENE, polydispersity index (PDI), zeta potential, and the mean droplet size of TENE were determined using a zeta potential and particle size analyzer (ELSZ-1000, Otsuka Electronics Co., Ltd., Osaka, Japan), with a detector angle of $90^{\circ}$ and a wavelength of $633 \mathrm{~nm}$ at $25^{\circ} \mathrm{C}$.

\subsection{Culture and differentiation of 3T3-L1 preadipocytes}

HepG2 cells and 3T3-L1 preadipocytes obtained from the Korean Cell Line Bank (Seoul, Korea) were maintained in Dulbecco's modified Eagle's medium (DMEM) supplemented with 10\% fetal bovine serum (Welgene, Daegu, Korea) or 10\% newborn calf serum (Thermo Fisher Scientific, MA, USA), respectively, in the presence of $100 \mathrm{U} / \mathrm{mL}$ penicillin and $100 \mu \mathrm{g} / \mathrm{mL}$ streptomycin, in a humidified atmosphere of $5 \% \mathrm{CO}_{2}$ at $37^{\circ} \mathrm{C}$. To differentiate 3T3-L1 preadipocytes into adipocytes, confluent 3T3-L1 cells maintained in DMEM containing 10\% fetal bovine serum (Welgene) were differentiated into adipocytes (starting on day 0 ) using a mixture of $1 \mu \mathrm{g} / \mathrm{mL}$ insulin, $1 \mu \mathrm{M}$ dexamethasone, and $0.5 \mathrm{mM}$ IBMX (MDI). The culture medium was then replaced with complete DMEM containing $1 \mu \mathrm{g} / \mathrm{mL}$ insulin, and the cells were incubated for another 4 days. Following this, the cells were incubated in complete DMEM, replacing the medium every other day. After incubation for 8 days, the extent of adipogenic differentiation was assessed.

\subsection{Determination of cell viability}

Cell viability was determined by the trypan blue exclusion method and MTT assay. For trypan blue exclusion, 3T3-L1 cells were seeded in 24 -well culture plates at a density of $1 \times 10^{4}$ cells per well. Following incubation for $24 \mathrm{~h}$, the cells were treated with the indicated concentrations of TENE for $24 \mathrm{~h}$. They were then washed with ice-cold phosphate-buffered saline (PBS) and harvested. After adding $0.4 \%$ trypan blue solution, the number of viable cells in the suspension was counted with a hemocytometer. MTT assay was performed 3T3-L1 cells seeded in 48 -well culture plates at a density of $3 \times 10^{3}$ cells per well. The cells were incubated with various concentrations of TENE for $24 \mathrm{~h}$, and then MTT solution was added to the culture medium. After incubation for $4 \mathrm{~h}$, the medium was removed, the crystal formazan was dissolved, and the absorbance at $570 \mathrm{~nm}$ was determined.

\subsection{Analysis of lipid content by Oil red $O$ staining}

3T3-L1 cells differentiated with MDI in the presence or absence of TENE were washed twice with ice-cold PBS and then fixed in $4 \%$ paraformaldehyde for $10 \mathrm{~min}$ at room temperature. After washing with PBS, the cells were stained with Oil Red O solution (6 parts $0.5 \%$ Oil Red O dye in isopropanol and 4 parts water) for $2 \mathrm{~h}$ at room temperature. Following extensive washing with distilled water, images were acquired using an Olympus FV-1000 confocal laser microscope (Olympus Corporation, Tokyo, Japan). The Oil red O stain was then solubilized in isopropanol for $5 \mathrm{~min}$ and quantified spectrophotometrically at $490 \mathrm{~nm}$ using an $\mathrm{XMark}^{\mathrm{TM}}$ Microplate Spectrophotometer (Bio-Rad, CA, USA).

\subsection{Nile Red staining}

Cells were washed twice with ice-cold PBS and then fixed with $4 \%$ paraformaldehyde for $10 \mathrm{~min}$ at room temperature. After washing with PBS, the cells were stained with Nile Red $(100 \mathrm{ng} / \mathrm{mL})$ for $5 \mathrm{~min}$ in the dark at room temperature. Images were acquired using an Olympus FV-1000 confocal laser microscope and the fluorescence was quantified using Olympus FV10-ASW 2.0 software. 


\subsection{Preparation of palmitate solution}

Fatty acid-free bovine serum albumin (BSA)-conjugated palmitate solution was prepared. Palmitate stock solution $(100 \mathrm{mM})$ dissolved in $100 \%$ ethanol by heating to $80^{\circ} \mathrm{C}$ was mixed with fatty acid-free BSA ( $2 \%$ in DMEM). The mixture was stirred at room temperature for $2 \mathrm{~h}$ and then diluted in culture media to give the final concentration indicated.

\subsection{Measurement of reactive oxygen species}

HepG2 cells seeded onto $35 \mathrm{~mm}$ cover glass-bottomed dishes (SPL Life Sciences, Seoul, Korea) were treated with $0.5 \mathrm{mM}$ palmitate in the presence or absence of TENE for $24 \mathrm{~h}$. The cells were incubated with $10 \mu \mathrm{M}$ CM-H DCF-DA for the final $30 \mathrm{~min}$. Following two washes with ice-cold PBS, green fluorescence corresponding to the concentration of intracellular ROS was quantified using a $520 \mathrm{~mm}$ long-pass filter and an Olympus FV-1000 laser fluorescence microscope.

\subsection{Western blot analysis}

Aliquots of whole cell lysates or tissue homogenates were subjected to SDS-polyacrylamide gel electrophoresis and the fractionated proteins were transferred onto Hybond- $\mathrm{P}^{+}$polyvinylidene difluoride membranes (GE Healthcare, Little Chalfont, UK). Membranes were blocked for $1 \mathrm{~h}$ at $37^{\circ} \mathrm{C}$ with $5 \%$ non-fat milk in Tris-buffered saline (TBS) containing 0.1\% Tween-20 and then incubated overnight at $4{ }^{\circ} \mathrm{C}$ with the indicated antibodies in TBS containing $0.1 \%$ Tween-20. Peroxidase-conjugated specific secondary antibody was then added to the membranes for $1 \mathrm{~h}$ at room temperature. After extensive washing in TBS containing $0.1 \%$ Tween-20, immunoreactive bands were detected using West-ZOL Plus (iNtRON Biotechnology).

\subsection{Animal study}

All animal studies were performed in accordance with the Korean College of Laboratory Animal Medicine's Guidelines for Animal Care and Use, and were approved by the Institutional Animal Care and Use Committee of Konkuk University (approval number: KU15140). Male ICR mice were obtained from Orient Bio, Inc. (Seongnam, Korea) and housed at $21 \pm 2{ }^{\circ} \mathrm{C}$ and $55 \pm 5 \%$ humidity, with a $12 \mathrm{~h}$ light/dark cycle, and acclimatized to the facility for 7 days. Seven-week-old mice were then randomly assigned to one of four groups: a normal diet group (ND, containing 19.2\% protein and 4.3\% fat; Altromin Spezialfutter GmbH \& Co., Lage, Germany), a HFD group (containing 24\% protein and $24 \%$ fat; Research Diets, Inc., NJ, USA), a HFD plus TENE (300 $\mathrm{mg} / \mathrm{kg} /$ day) group, and a ND plus TENE (300 mg/kg/day) group. TENE was administrated to the mice once daily by gavage for 8 weeks. After this period, the mice were euthanized and epididymal adipose tissue was excised and either frozen in liquid nitrogen or fixed in $4 \%$ paraformaldehyde solution for further analysis. Plasma total cholesterol, triglycerides, high-density lipoprotein (HDL), and low-density lipoprotein (LDL) were measured by Seoul Clinical Laboratories Services (Seoul, Korea).

\subsection{Hematoxylin and Eosin staining}

For histological examination of adipose tissue, epididymal adipose tissue fixed with $4 \%$ paraformaldehyde was embedded in paraffin. Paraffin blocks were cut into $4 \mu \mathrm{m}$ slices, which were mounted on glass slides, deparaffinized, and rehydrated. The adipose sections were then stained with Hematoxylin and Eosin (H\&E) and photographed under a light microscope.

\subsection{Statistical analysis}

Data are expressed as mean \pm standard error (SE). Statistical significance was determined by ANOVA followed by post-hoc Bonferroni or Student's t-test, as appropriate. $P<0.05$ was considered statistically significant.

\section{Results and discussion}

\subsection{Properties of TENE}

To determine the physicochemical properties and bioavailability of nanoparticles for encapsulation, we analyzed the particle size and size distribution of TENE powder and TENE. The mean droplet size of TENE powder and TENE were $492.2 \mathrm{~nm}$ and $323.6 \mathrm{~nm}$, respectively, indicating a single spectrum of size distribution. The curcumin content of TENE powder was $3.3 \mu \mathrm{g} / \mathrm{mg}$, which was 15 times lower than that of turmeric extract powder (Table 1) (equation 1).

$$
\text { Food efficiency ratio }=\frac{\text { weight gain }(g)}{\text { food intake }(g)} \times 100
$$

\subsection{Effects of TENE on intracellular lipid accumulation in 3T3-L1 adipocytes}

To determine the optimal dose of TENE for 3T3-L1 cells, cell viability was assessed using the trypan blue exclusion method. When cells were incubated in the presence of a range of concentrations of TENE $(0,1,2,5,10$, or $30 \mu \mathrm{g} / \mathrm{mL})$ for $24 \mathrm{~h}$, a toxic effect of TENE was not observed up to $10 \mu \mathrm{g} / \mathrm{mL}$; therefore, $10 \mu \mathrm{g} / \mathrm{mL}$ TENE was used in subsequent experiments (Figure 1A).

Table 1. Effects of TENE on body mass, food intake, and food efficiency.

\begin{tabular}{|c|c|c|c|c|c|}
\hline \multirow{2}{*}{ Groups } & Initial mass & Final mass & Mass gain & Food intake & Food efficiency \\
\hline & (g/mouse) & (g/mouse) & (g/mouse/8 weeks) & (g/mouse/8 weeks) & ratio (\%) \\
\hline ND & $29.5 \pm 0.8$ & $39.9 \pm 0.9$ & 10.4 & 2109.5 & 0.4 \\
\hline HFD & $28.5 \pm 0.6$ & $48.0 \pm 2.3$ & 19.4 & 1861.5 & 1 \\
\hline HFD + TENE & $28.7 \pm 0.5$ & $51.8 \pm 2.7$ & 23 & 4120.3 & 0.5 \\
\hline TENE & $29.8 \pm 0.7$ & $41.0 \pm 1.2$ & 11.1 & 1992.4 & 0.5 \\
\hline
\end{tabular}

Values are mean \pm SE $(n=8)$. 
A

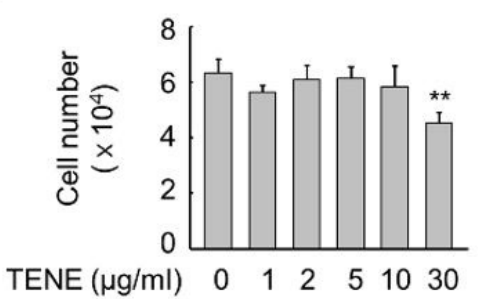

C

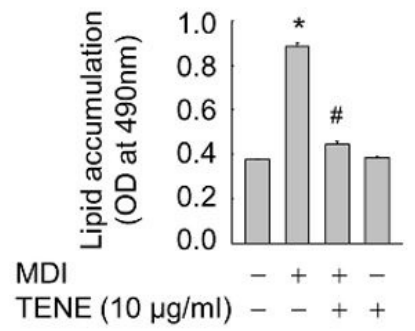

D

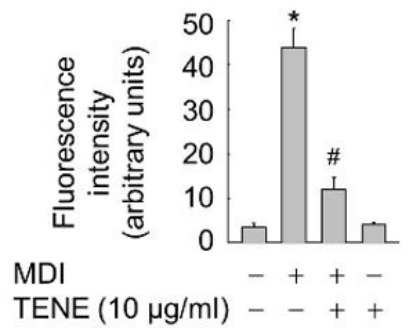

B
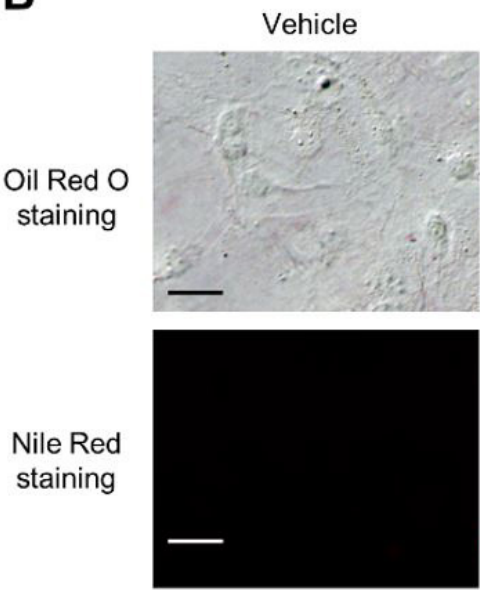
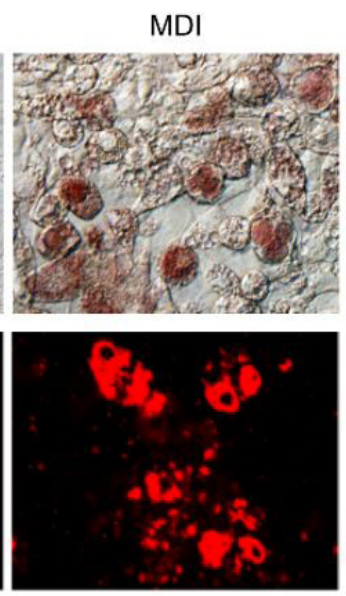

$\mathrm{MDI}+$ $\operatorname{TENE}(10 \mu \mathrm{g} / \mathrm{ml})$
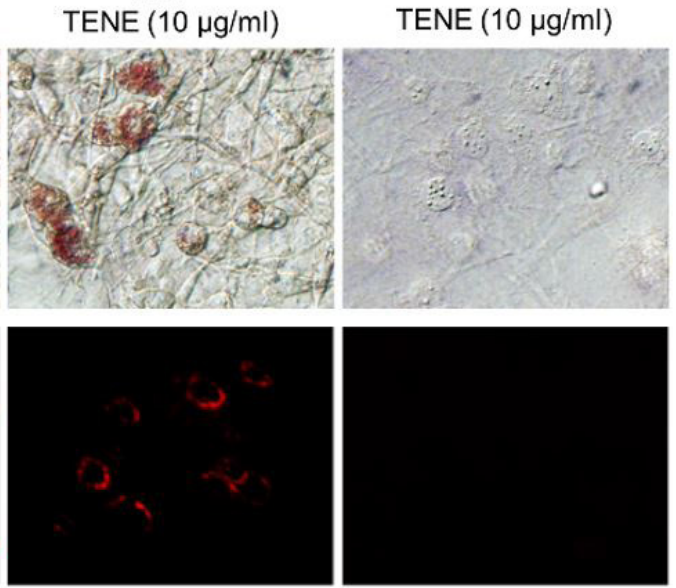

Figure 1. Effect of TENE on intracellular lipid accumulation in 3T3-L1 cells. (A) Cells grown to near confluence in 24-well plates were incubated with the indicated concentrations of TENE for $24 \mathrm{~h}$, after which cell viability was assessed by the trypan blue exclusion method. Data are mean \pm S.E. $(n=4)$. (B-D) Cells seeded in $60 \mathrm{~mm}$ culture dishes were grown to confluence and then stimulated with MDI for 2 days in the presence or absence of $10 \mu \mathrm{g} / \mathrm{ml}$ TENE. Cells were then incubated for an additional 4 days in complete medium containing $1 \mu \mathrm{g} / \mathrm{ml}$ insulin, and then followed incubation in complete medium for 2 days, replacing the medium every other day. After washing with PBS, the cells were fixed and stained with Oil Red O or Nile Red. Representative microscopic images are shown (B), and intracellular lipid content was assessed by measuring optical density at $490 \mathrm{~nm}(\mathrm{C})$ or fluorescence intensity (D). Bar, $100 \mu \mathrm{m}$. Data are expressed as mean \pm S.E. $(\mathrm{n}=6) .{ }^{*} \mathrm{p}<0.01,{ }^{* *} \mathrm{p}<0.05 \mathrm{compared}$ with the untreated group; $\# \mathrm{p}<0.01$ compared with the MDI-treated group.

Because turmeric extract is a potential therapy for obesity (Ho et al., 2012; Septembre-Malaterre et al., 2016), we assessed whether TENE might affect adipogenesis in 3T3-L1 adipocytes. When 3T3-L1 cells were treated with MDI for 8 days, intracellular lipid content was significantly increased, according to Oil Red O staining. However, this increase in lipid content was significantly lower in the presence of TENE (Figure 1B and 1C). Similar results were obtained when the cells were stained with Nile Red dye to quantify intracellular triglyceride (Figure 1B and 1D). In line with these effects of TENE, polyphenols extracted from C. longa inhibit insulin-induced lipid accumulation and oxidative stress-related inflammatory response in 3T3-L1 adipocytes by regulating the expression of the adipokine adiponectin, and antioxidant enzymes, such as superoxide dismutase and catalase (Septembre-Malaterre et al., 2016). In addition, turmeric extracts exhibit powerful anti-obesity effects by stimulating lipolysis in 3T3-L1 adipocytes and animal models of obesity, in which they regulate glucose uptake, leptin secretion, and thus energy metabolism (Lee et al., 2010; Song \& Choi, 2016). These findings are consistent with our data demonstrating the anti-adipogenic activity of TENE, which leads to reduced lipid accumulation in a cellular model. The data suggest that TENE may act by regulating cellular differentiation, which makes it suitable as a potential therapeutic agent for obesity (Ho et al., 2012; Song \& Choi, 2016).

\subsection{Effects of TENE on the expression of adipogenic genes in 3T3-L1 adipocytes}

To dissect the mechanisms underlying the inhibitory effect of TENE on 3T3-L1 preadipocyte differentiation, the effect of TENE on the expression of the key adipogenic transcription factors PPAR- $\gamma$ and C/EBP- $\alpha$ was evaluated. PPAR- $\gamma$ and $\mathrm{C} / \mathrm{EBP}-\alpha$ protein levels dramatically increased following incubation with MDI solution for 8 days, whereas the levels of both proteins significantly lowered in the presence of TENE 
A

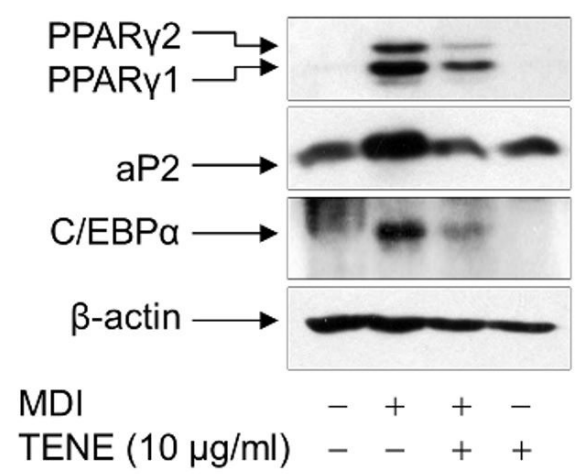

B

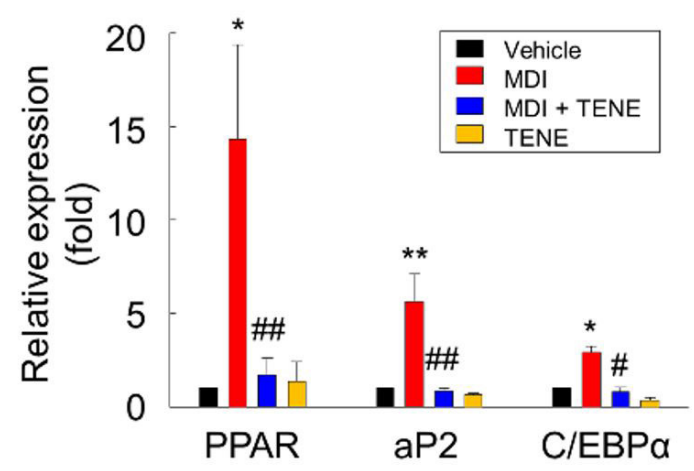

Figure 2. Effect of TENE on the expression of adipogenic genes in 3T3-L1 cells. (A and B) Following incubation for 8 days in the presence or absence of MDI and/or TENE, the cells were washed with PBS and then lysed. The expression levels of PPAR- $\gamma, \mathrm{C} / \mathrm{EBP}-\alpha$, and aP2 were quantified by immunoblot analysis using the indicated antibodies. Representative blots (A) and densitometric measurements are shown (B). ${ }^{\star} \mathrm{p}<0.01$, ${ }^{* *} \mathrm{p}<0.05$ compared with the untreated group; $\# \mathrm{p}<0.01$, \#\#p<0.05 compared with the MDI-treated group.

(Figure 2A and 2B). Furthermore, TENE also suppressed the expression of aP2, a marker of mature adipocytes (Figure 2A and 2B), suggesting that TENE inhibits the adipogenic differentiation of 3T3-L1 preadipocytes by downregulating expression of the transcription factors that initiate adipogenesis. Control of PPAR- $\gamma$ and $\mathrm{C} / \mathrm{EBP}-\alpha$ expression is the major regulatory mechanism involved in adipogenic differentiation (Cristancho \& Lazar, 2011; Guo et al., 2015). Consistent with this concept, we have shown that MDI-induced adipogenic differentiation of 3T3-L1 cells is dramatically inhibited in the presence of TENE, which is associated with the downregulation of these key adipogenic factors. Although the biological effect of such turmeric extract-mediated anti-adipogenic activity has been documented in multiple reports (Lee et al., 2010; Septembre-Malaterre et al., 2016; Song \& Choi, 2016), the effect of turmeric extract on the expression of PPAR- $\gamma$ and C/EBP- $\alpha$ has not previously been shown. Additional studies on the anti-adipogenic effects of turmeric extract will be important to further elucidate the mechanisms underpinning its anti-obesity effects.

\subsection{Effects of TENE on palmitate-induced lipid accumulation and ROS production in HepG2 cells}

An imbalance in lipid synthesis and export in hepatocytes results in lipid accumulation and lipotoxicity (Leamy et al., 2014). Therefore, we examined the effects of TENE on the viability of HepG2 cells exposed to palmitate. While cell viability was dramatically reduced by palmitate treatment, this effect was ameliorated in a dose-dependent manner in HepG2 cells exposed to TENE (Figure 3A).

To establish whether this TENE-mediated cytoprotection was due to suppression of lipid accumulation in HepG2 cells treated with palmitate, we measured the number and size of intracellular lipid vacuoles using Nile Red staining. Palmitate-induced lipid vacuoles were significantly fewer and smaller in the presence of $10 \mu \mathrm{g} / \mathrm{mL}$ TENE, indicating that TENE protects hepatocytes from palmitate-induced lipid accumulation (Figure 3B and 3C).
The beneficial effects of turmeric extract on hepatic disease have also been demonstrated in the chemical-induced liver injury in which administration of turmeric extract was associated with a significant reduction in the hepatic oxidative states (Uchio et al., 2017; Lee et al., 2016). A dietary supplement containing turmeric extract also prevented the development of nonalcoholic fatty liver disease (NAFLD) by modulating the levels of serum glucose and leptin in patients with NAFLD (Navekar et al., 2017). These observations are in line with our present results demonstrating that TENE can improve palmitate-induced hepatotoxicity by regulating cellular accumulation of lipid.

To elucidate the mechanisms underlying the beneficial effect of TENE on cell viability, we also examined whether TENE affected the accumulation of intracellular ROS in HepG2 cells using the fluorescent probe $\mathrm{H}_{2} \mathrm{DCF}-\mathrm{DA}$. Palmitate significantly enhanced intracellular ROS production in HepG2 cells, whereas this was almost completely prevented by TENE (Figure 4 ). In line with this result, a hot water extract of turmeric inhibits ethanol-induced liver injury by inhibiting hepatic oxidative stress and production of inflammatory cytokines tumor necrosis factor (TNF)- $\alpha$ and interleukin (IL)-6 (Uchio et al., 2017). In addition, turmeric extract and its active compound curcumin also exhibited hepatoprotective activity against carbon tetrachloride-induced injury in mice by suppressing hepatic oxidative stress (Lee et al., 2016). These observations indicate that TENE may be effective in reducing lipid- or chemical-induced hepatocellular damage via anti-oxidative activity, in addition to its anti-adipogenic activity.

\subsection{Effects of TENE on the expression of adipogenic genes and adipocyte size in mice fed a HFD}

Because TENE downregulated the expression of the adipogenic transcription factors PPAR- $\gamma$ and C/EBP- $\alpha$ during MDI-induced adipogenic differentiation of 3T3-L1 cells, we examined the effects of TENE in the epididymal adipose tissue of mice fed a HFD. Consistent with the above results, TENE significantly attenuated the HFD-induced expression of PPAR- $\gamma$ and C/EBP- $\alpha$. 
A
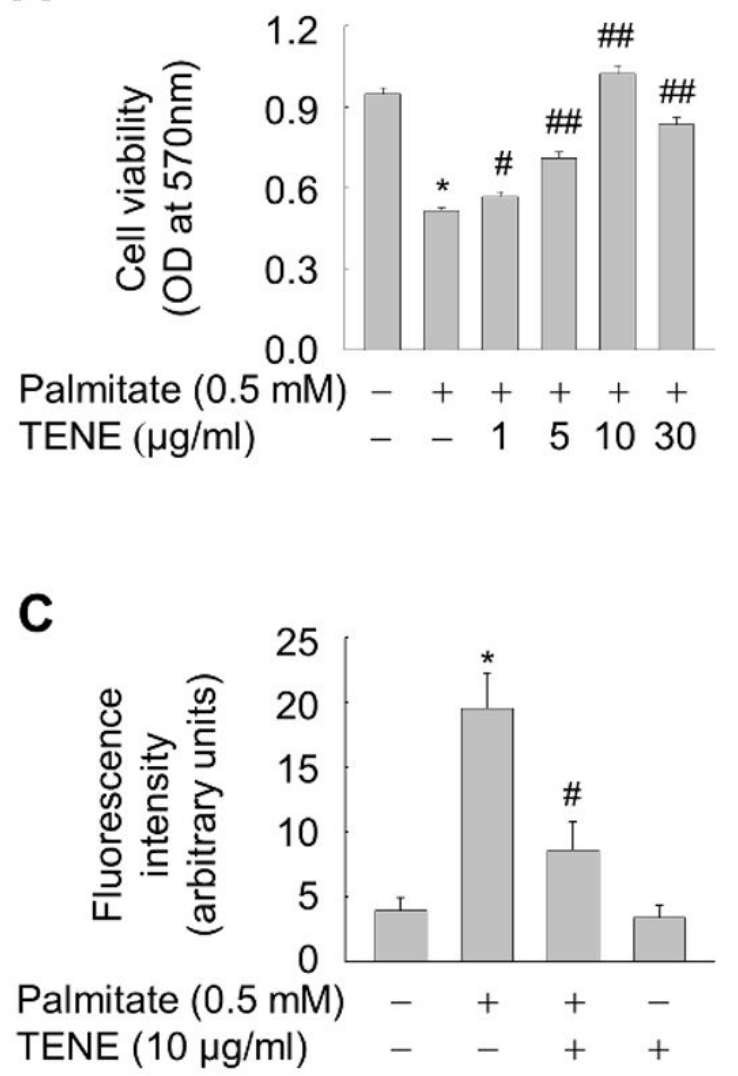

B

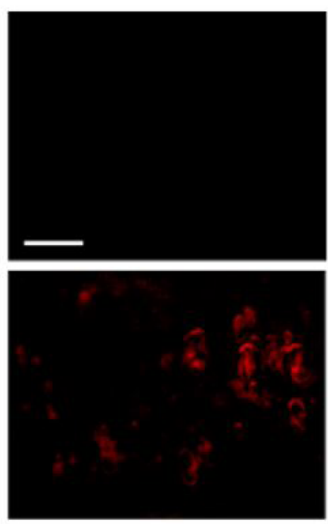

Vehicle

Palmitate

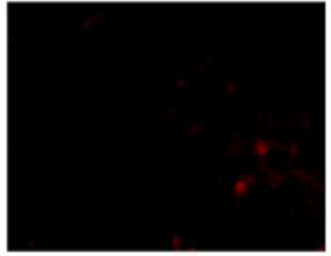

Palmitate + TENE $(10 \mu \mathrm{g} / \mathrm{ml})$

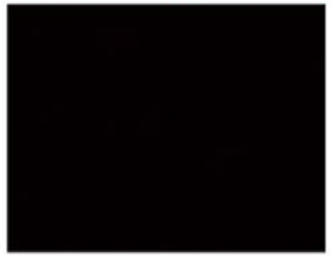

TENE $(10 \mu \mathrm{g} / \mathrm{ml})$

Figure 3. Effect of TENE on palmitate-induced lipotoxicity and lipid accumulation in HepG2 cells. (A) Cells pretreated with various concentrations of TENE for $1 \mathrm{~h}$ were then incubated with $0.5 \mathrm{mM}$ palmitate. After incubation for $21 \mathrm{~h}$, cell viability was measured by MTT assay. (B and C) HepG2 cells were incubated with $0.5 \mathrm{mM}$ palmitate in the presence or absence of $10 \mu \mathrm{g} / \mathrm{ml}$ TENE for $24 \mathrm{~h}$, and then stained with Nile Red solution. Representative fluorescence microscopic images are shown (B) and intracellular triglyceride accumulation was quantified in six random low power fields $(\mathrm{C})$. The fluorescence intensity was measured and expressed as mean \pm S.E. $(\mathrm{n}=6)$. Bar, $100 \mu \mathrm{m}$. ${ }^{*} \mathrm{p}<0.01$ compared with the untreated group; $\# \mathrm{p}<0.01, \# \# \mathrm{p}<0.05$ compared with the palmitate-treated group.

A

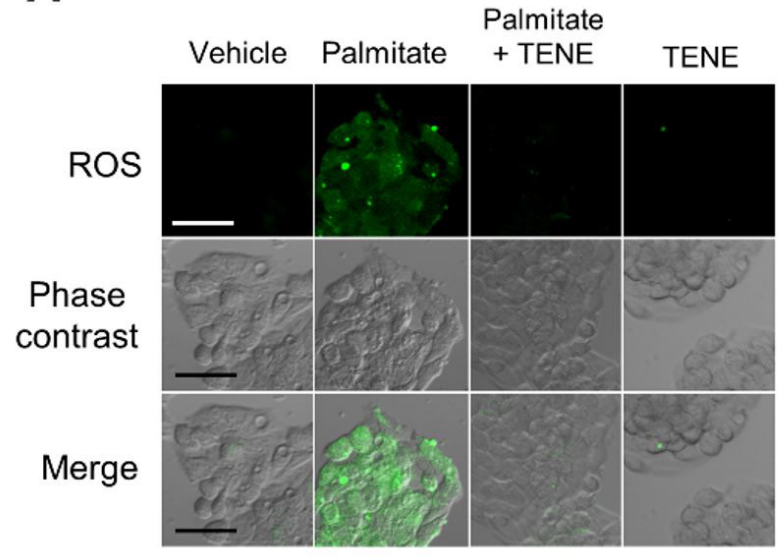

B

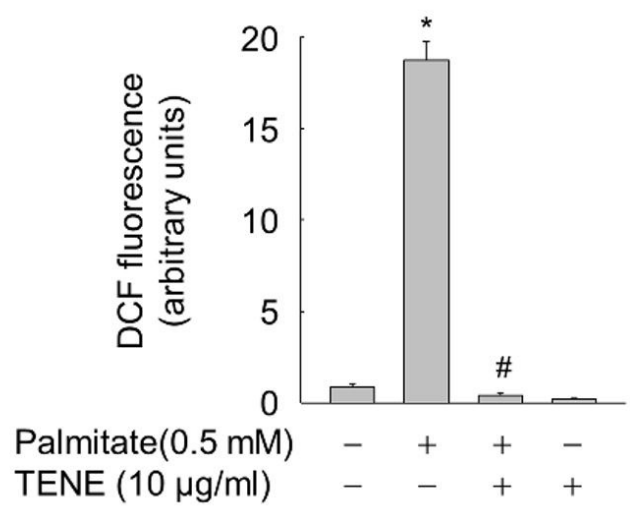

Figure 4. Effect of TENE on ROS production by palmitate-treated HepG2 cells. (A and B) Cells pretreated with $10 \mu \mathrm{g} / \mathrm{ml} \mathrm{TENE}$ for $1 \mathrm{~h}$ were incubated with $0.5 \mathrm{mM}$ palmitate. Following incubation for $21 \mathrm{~h}$, the cells were treated with a peroxide-sensitive dye, $\mathrm{H} 2 \mathrm{DCF}-\mathrm{DA}$ (10 $\mu \mathrm{M})$, during the final $30 \mathrm{~min}$ of the incubation. The intracellular ROS signals were visualized (A) and quantified (B) by confocal laser scanning microscopy. Bar, $100 \mu \mathrm{m} .{ }^{*} \mathrm{p}<0.01$ compared with the untreated group; $\# \mathrm{p}<0.01$ compared with the palmitate-treated group. 
A

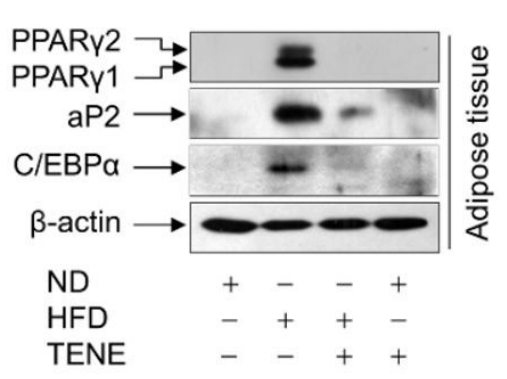

B

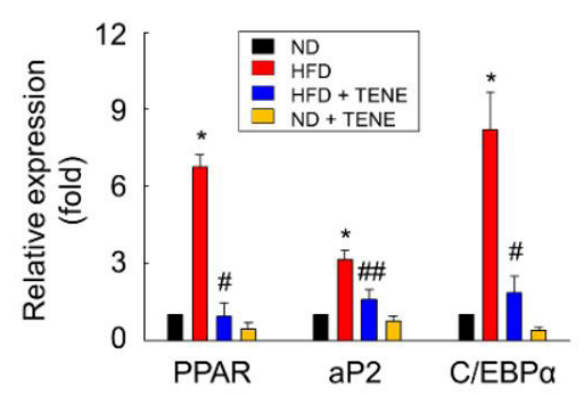

C

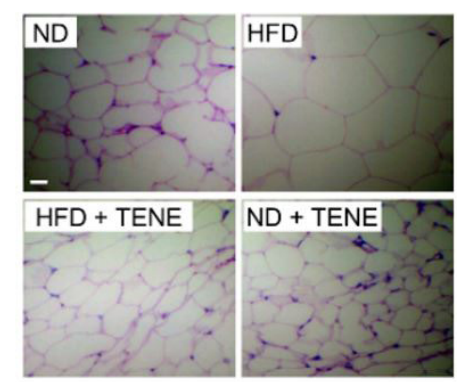

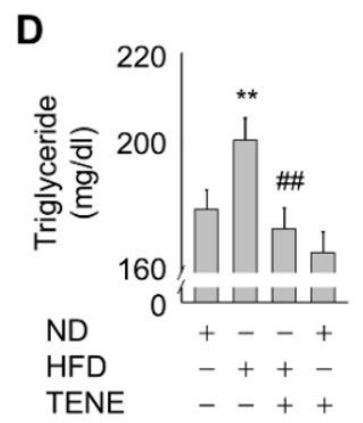
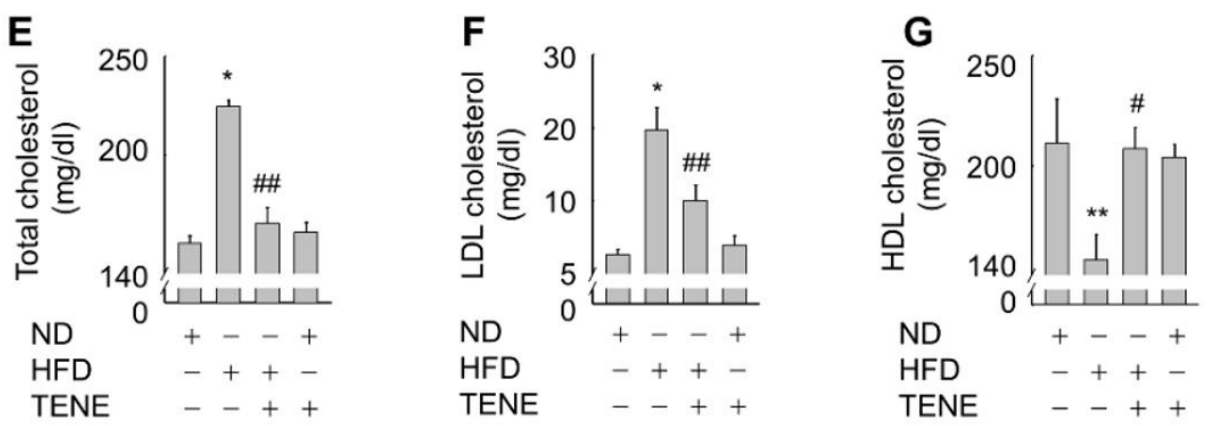

Figure 5. Effect of TENE on the expression of adipogenic genes, adipocyte size, and circulating lipid profile. Mice were fed with either a ND or HFD and administered with or without TENE for 8 weeks. (A and B) Lysates of epididymal adipose tissue were subjected to immunoblot analysis using indicated antibodies. Representative blots (A) and densitometric measurements are shown (B). (C) Epididymal adipose tissue was sectioned and the sizes of the adipocytes were analyzed by $\mathrm{H} \& \mathrm{E}$ staining. The sections were obtained from four independent experiments and representative images are shown. Bar, $50 \mu \mathrm{m}$. (D-G) Whole blood was obtained at the end-point of the experiment and serum was separated after sedimentation for $2 \mathrm{~h}$ at room temperature. The circulating concentrations of total cholesterol (D), triglyceride (E), LDL (F), and HDL (G) were analyzed and plotted. Data are mean \pm S.E. $(n=6) .{ }^{*} \mathrm{p}<0.01,{ }^{*} \mathrm{p}<0.05$ compared with the ND-fed group; $\# \mathrm{p}<0.01, \# \# \mathrm{p}<0.05$ compared with the HFD-fed group.

In addition, aP2 protein was also lower in epididymal adipose obtained from mice given TENE and a HFD versus mice fed a HFD alone (Figure 5A and 5B). Furthermore, TENE also reduced the number and size of adipocytes in the epididymal adipose tissue (Figure 5C), suggesting that it might reduce adiposity in HFD-fed obese mice by downregulating the expression of adipogenic and lipogenic genes induced by HFD.

\subsection{Effects of TENE on the serum lipid profile of HFD-fed mice}

To establish whether the anti-adipogenic effects of TENE were linked to changes in whole-body lipid metabolism, the effect of TENE on serum lipid profile was evaluated in the HFD-fed mice. The levels of triglyceride, total cholesterol, and low-density lipoprotein (LDL) were significantly increased in the serum of mice fed a HFD, compared with those of normal diet (ND)-fed mice, but these increases were significantly less in the presence of TENE (by $4.5 \%, 9.4 \%$, and 9.9\%, respectively) (Figure 5D, 5E, and 5F). By contrast, oral administration of TENE to HFD-fed mice significantly ameliorated the HFD-induced suppression of high-density lipoprotein (HDL, by $6.2 \%$ ) (Figure 5G). Consistent with our observations, previous studies have reported that turmeric extract-mediated blockade of adipogenic differentiation is associated with improved cellular energy metabolism in animal models of obesity (Lee et al., 2010; Septembre-Malaterre et al., 2016; Song \& Choi, 2016). The effect of TENE on the regulation of adipogenic differentiation has not been fully investigated previously, but the present observations suggest that TENE contains anti-adipogenic compounds that may be beneficial for obese patients. TENE-mediated inhibition of adipogenic differentiation in adipose tissue may reduce the prevalence of associated metabolic disorders by improving the circulating lipid and cholesterol profile.

\section{Conclusion}

The present study shows that TENE significantly inhibited the adipogenic differentiation of 3T3-L1 preadipocytes by suppressing expression of PPAR- $\gamma$ and C/EBP- $\alpha$, thereby reducing intracellular lipid accumulation. Furthermore, oral administration of TENE to mice reduced the expression of these key adipogenic transcription factors in epididymal adipose tissue. These effects were accompanied by improvements in circulating lipid and cholesterol profile, indicative of whole body changes in lipid turnover. These results suggest that TENE has promising anti-adipogenic activity in both in vitro and in vivo models, which implies that it may have potential as an anti-obesity drug. 


\section{Acknowledgements}

This work was supported by Konkuk University in 2018.

\section{References}

Aggarwal, B. B., Yuan, W., Li, S., \& Gupta, S. C. (2013). Curcuminfree turmeric exhibits anti-inflammatory and anticancer activities: Identification of novel components of turmeric. Molecular Nutrition \& Food Research, 57(9), 1529-1542. http://dx.doi.org/10.1002/ mnfr.201200838. PMid:23847105.

Araújo, C. C., \& Leon, L. L. (2001). Biological activities of Curcuma longa L. Memorias do Instituto Oswaldo Cruz, 96(5), 723-728. http:// dx.doi.org/10.1590/S0074-02762001000500026. PMid:11500779.

Coe, N. R., Simpson, M. A., \& Bernlohr, D. A. (1999). Targeted disruption of the adipocyte lipid-binding protein ( $\mathrm{aP} 2$ protein) gene impairs fat cell lipolysis and increases cellular fatty acid levels. Journal of Lipid Research, 40(5), 967-972. PMid:10224167.

Cristancho, A. G., \& Lazar, M. A. (2011). Forming functional fat: a growing understanding of adipocyte differentiation. Nature Reviews. Molecular Cell Biology, 12(11), 722-734. http://dx.doi.org/10.1038/ nrm3198. PMid:21952300.

Farmer, S. R. (2006). Transcriptional control of adipocyte formation. Cell Metabolism, 4(4), 263-273. http://dx.doi.org/10.1016/j. cmet.2006.07.001. PMid:17011499.

Gregoire, F. M., Smas, C. M., \& Sul, H. S. (1998). Understanding adipocyte differentiation. Physiological Reviews, 78(3), 783-809. http://dx.doi.org/10.1152/physrev.1998.78.3.783. PMid:9674695.

Guo, L., Li, X., \& Tang, Q. Q. (2015). Transcriptional regulation of adipocyte differentiation: a central role for CCAAT/enhancer-binding protein (C/EBP) $\beta$. The Journal of Biological Chemistry, 290(2), 755761. http://dx.doi.org/10.1074/jbc.R114.619957. PMid:25451943.

Guo, L., Li, X., Huang, J. X., Huang, H. Y., Zhang, Y. Y., Qian, S. W., Zhu, H., Zhang, Y. D., Liu, Y., Liu, Y., Wang, K. K., \& Tang, Q. Q. (2012). Histone demethylase $\mathrm{Kdm} 4 \mathrm{~b}$ functions as a co-factor of C/ EBP $\beta$ to promote mitotic clonal expansion during differentiation of 3T3-L1 preadipocytes. Cell Death and Differentiation, 19(12), 1917-1927. http://dx.doi.org/10.1038/cdd.2012.75. PMid:22722334.

Gupta, S. C., Sung, B., Kim, J. H., Prasad, S., Li, S., \& Aggarwal, B. B. (2013). Multitargeting by turmeric, the golden spice: From kitchen to clinic. Molecular Nutrition \& Food Research, 57(9), 1510-1528. http://dx.doi.org/10.1002/mnfr.201100741. PMid:22887802.

Haslam, D. W., \& James, W. P. (2005). Obesity. Lancet, 366(9492), 1197-1209. http://dx.doi.org/10.1016/S0140-6736(05)67483-1. PMid:16198769.

Ho, J. N., Jang, J. Y., Yoon, H. G., Kim, Y., Kim, S., Jun, W., \& Lee, J. (2012). Anti-obesity effect of a standardised ethanol extract from Curcuma longa L. fermented with Aspergillus oryzae in ob/ob mice and primary mouse adipocytes. Journal of the Science of Food and Agriculture, 92(9), 1833-1840. http://dx.doi.org/10.1002/jsfa.5592. PMid:22278718.

Huang, M. T., Lysz, T., Ferraro, T., Abidi, T. F., Laskin, J. D., \& Conney, A. H. (1991). Inhibitory effects of curcumin on in vitro lipoxygenase and cyclooxygenase activities in mouse epidermis. Cancer Research, 51(3), 813-819. PMid:1899046.

Huang, M. T., Smart, R. C., Wong, C. Q., \& Conney, A. H. (1988). Inhibitory effect of curcumin, chlorogenic acid, caffeic acid, and ferulic acid on tumor promotion in mouse skin by 12-O-tetradecanoylphorbol13-acetate. Cancer Research, 48(21), 5941-5946. PMid:3139287.

Kopelman, P. G. (2000). Obesity as a medical problem. Nature, 404(6778), 635-643. http://dx.doi.org/10.1038/35007508. PMid:10766250.
Leamy, M., Clarke, E., Le Boutillier, C., Bird, V., Janosik, M., Sabas, K., Riley, G., Williams, J., \& Slade, M. (2014). Implementing a complex intervention to support personal recovery: a qualitative study nested within a cluster randomised controlled trial. PLoS One, 9(5), e97091. http://dx.doi.org/10.1371/journal.pone.0097091. PMid:24875748.

Lee, H. Y., Kim, S. W., Lee, G. H., Choi, M. K., Jung, H. W., Kim, Y. J., Kwon, H. J., \& Chae, H. J. (2016). Turmeric extract and its active compound, curcumin, protect against chronic CCl4-induced liver damage by enhancing antioxidation. BMC Complementary and Alternative Medicine, 16(1), 316. http://dx.doi.org/10.1186/s12906016-1307-6. PMid:27561811.

Lee, J., Yoon, H. G., Lee, Y. H., Park, J., You, Y., Kim, K., Jang, J. Y., Yang, J. W., \& Jun, W. (2010). The potential effects of ethyl acetate fraction from Curcuma longa L. on lipolysis in differentiated 3T3-L1 adipocytes. Journal of Medicinal Food, 13(2), 364-370. http://dx.doi. org/10.1089/jmf.2009.1276. PMid:20412020.

Mukhopadhyay, A., Basu, N., Ghatak, N., \& Gujral, P. K. (1982). Antiinflammatory and irritant activities of curcumin analogues in rats. Agents and Actions, 12(4), 508-515. http://dx.doi.org/10.1007/ BF01965935. PMid:7180736.

Navekar, R., Rafraf, M., Ghaffari, A., Asghari-Jafarabadi, M., \& Khoshbaten, M. (2017). Turmeric Supplementation Improves Serum Glucose Indices and Leptin Levels in Patients with Nonalcoholic Fatty Liver Diseases. Journal of the American College of Nutrition, 36(4), 261-267. http://dx.doi.org/10.1080/07315724.2016.126759 7. PMid:28443702.

Rasmussen, H. B., Christensen, S. B., Kvist, L. P., \& Karazmi, A. (2000). A simple and efficient separation of the curcumins, the antiprotozoal constituents of Curcuma longa. Planta Medica, 66(4), 396-398. http:// dx.doi.org/10.1055/s-2000-8533. PMid:10865470.

Reddy, A. C., \& Lokesh, B. R. (1992). Studies on spice principles as antioxidants in the inhibition of lipid peroxidation of rat liver microsomes. Molecular and Cellular Biochemistry, 111(1-2), 117124. PMid:1588934.

Reddy, A. C., \& Lokesh, B. R. (1994). Studies on the inhibitory effects of curcumin and eugenol on the formation of reactive oxygen species and the oxidation of ferrous iron. Molecular and Cellular Biochemistry, 137(1), 1-8. http://dx.doi.org/10.1007/BF00926033. PMid:7845373.

Rosen, E. D., \& MacDougald, O. A. (2006). Adipocyte differentiation from the inside out. Nature Reviews. Molecular Cell Biology, 7(12), 885-896. http://dx.doi.org/10.1038/nrm2066. PMid:17139329.

Sathishkumar, M., Sneha, K., \& Yun, Y. S. (2010). Immobilization of silver nanoparticles synthesized using Curcuma longa tuber powder and extract on cotton cloth for bactericidal activity. Bioresource Technology, 101(20), 7958-7965. http://dx.doi.org/10.1016/j. biortech.2010.05.051. PMid:20541399.

Septembre-Malaterre, A., Le Sage, F., Hatia, S., Catan, A., Janci, L., \& Gonthier, M. P. (2016). Curcuma longa polyphenols improve insulin-mediated lipid accumulation and attenuate proinflammatory response of 3T3-L1 adipose cells during oxidative stress through regulation of key adipokines and antioxidant enzymes. BioFactors (Oxford, England), 42(4), 418-430. http://dx.doi.org/10.1002/ biof.1288. PMid:27094023.

Shepherd, P. R., Gnudi, L., Tozzo, E., Yang, H., Leach, F., \& Kahn, B. B. (1993). Adipose cell hyperplasia and enhanced glucose disposal in transgenic mice overexpressing GLUT4 selectively in adipose tissue. The Journal of Biological Chemistry, 268(30), 22243-22246. PMid:8226728.

Song, W. Y., \& Choi, J. H. (2016). Korean Curcuma longa L. induces lipolysis and regulates leptin in adipocyte cells and rats. Nutrition 
Research and Practice, 10(5), 487-493. http://dx.doi.org/10.4162/ nrp.2016.10.5.487. PMid:27698955.

Spalding, K. L., Arner, E., Westermark, P. O., Bernard, S., Buchholz, B. A., Bergmann, O., Blomqvist, L., Hoffstedt, J., Näslund, E., Britton, T., Concha, H., Hassan, M., Rydén, M., Frisén, J., \& Arner, P. (2008). Dynamics of fat cell turnover in humans. Nature, 453(7196), 783-787. http://dx.doi.org/10.1038/nature06902. PMid:18454136.

Uchio, R., Higashi, Y., Kohama, Y., Kawasaki, K., Hirao, T., Muroyama, K., \& Murosaki, S. (2017). A hot water extract of turmeric (Curcuma longa) suppresses acute ethanol-induced liver injury in mice by inhibiting hepatic oxidative stress and inflammatory cytokine production. Journal of Nutritional Science, 6, e3. http://dx.doi. org/10.1017/jns.2016.43. PMid:28620478.
Wakabayashi, K., Okamura, M., Tsutsumi, S., Nishikawa, N. S., Tanaka, T., Sakakibara, I., Kitakami, J., Ihara, S., Hashimoto, Y., Hamakubo, T., Kodama, T., Aburatani, H., \& Sakai, J. (2009). The peroxisome proliferator-activated receptor gamma/retinoid $\mathrm{X}$ receptor alpha heterodimer targets the histone modification enzyme PR-Set7/Setd8 gene and regulates adipogenesis through a positive feedback loop. Molecular and Cellular Biology, 29(13), 3544-3555. http://dx.doi.org/10.1128/MCB.01856-08. PMid:19414603.

Yano, Y., Satomi, M., \& Oikawa, H. (2006). Antimicrobial effect of spices and herbs on Vibrio parahaemolyticus. International Journal of Food Microbiology, 111(1), 6-11. http://dx.doi.org/10.1016/j. ijfoodmicro.2006.04.031. PMid:16797760. 